\title{
Effects of Multicomponent Training on Functional Fitness and Quality of Life in Older Women: A Randomized Controlled Trial
}

\begin{abstract}
Antônio Gomes de Resende-Neto ${ }^{1 *}$, Matheus Amarante do Nascimento ${ }^{2}$, José Carlos Aragão-Santos ${ }^{1}$, Bruna Caroline Oliveira Andrade ${ }^{1}$, Alan Bruno Silva Vasconcelos ${ }^{1}$, Danilo Rodrigues Pereira da Silva ${ }^{1}$, Raquel Simões Mendes Netto ${ }^{1}$, Josimari Melo de Santana ${ }^{3}$ and Marzo Edir Da Silva Grigoletto ${ }^{1}$
\end{abstract}

\author{
${ }^{1}$ Department of Physical Education, Federal University of Sergipe, Brazil \\ ${ }^{2}$ Metabolism, Nutrition, and Exercise Laboratory, Londrina State University, Londrina, Brazil \\ ${ }^{3}$ Department of Physical Therapy, Federal University of Sergipe, Brazil
}

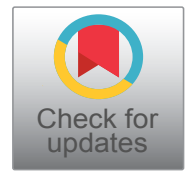

*Corresponding author: Antonio Gomes de Resende Neto, Department of Physical Education, Center of Biological and Health Sciences, Federal University of Sergipe, Rua Projetada III, 189, BL12 AP304, Bairro Rosa Elze, CEP: 49100-00, São Cristóvão- SE, Brazil

\begin{abstract}
Purpose: This study aimed to analyze the effects of twelve weeks of multicomponent training on functional fitness and quality of life in elderly women.

Methods: Sixty-two older women were randomized into a multicomponent group (MG: $n=32,65.28 \pm 4.96$ years) or a stretching group (SG: $n=32,64.40 \pm 3.68$ years). MG performed joint mobility exercises, walking, muscle strength exercises and intermittent activities. SG has performed flexibility exercises with minimal physical effort. In order to verify the functional fitness, the Senior Fitness Test battery was used and the quality of life was verified by means of the WHOQOL BREF questionnaire in the pre and post 12 weeks of training. Analysis of variance (ANOVA) $2 \times 2$ for repeated measures was used for comparisons between groups for all variables.

Results: At the end of the intervention, MG presented statistically significant improvements in all variables in relation to the initial values. When compared to SG, promoted statistically significant adaptations in the variables: balance/ agility $(p=0.001,+11.92 \%)$, lower limb strength $(p=0.001$, $+20.62 \%)$, upper limb strength $(0.001,+17.72 \%)$, cardiorespiratory capacity $(p=0.021,+6.19 \%)$ and quality of life $(p$ $=0.031,+7.95 \%$ ). However, in posterior chain flexibility and shoulder mobility, no differences were observed between groups ( $p \geq 0.05$ ).

Conclusion: This multicomponent protocol is efficient to improve functional fitness and quality of life in physically active elderly women, suggesting its use in physical exercise programs.
\end{abstract}

\section{Keywords}

Resistance training, Daily living activities, Well-being

\section{Introduction}

The participation in regular physical exercise programs contributes positively to health, quality of life, and independence of the older adult, by stimulating conditioning capacities, such as muscle power, balance, cardiorespiratory endurance and other variables related to human functionality $[1,2]$. According to the positioning of the American College of Sports Medicine [3], physical exercise programs for older adults should contemplate endurance exercises, to improve aspects of cardiovascular function; balance exercises to reduce the risk of falls and flexibility exercises to maintain adequate levels of mobility in the joints commonly used in daily life. In the last years, it has been noted that health promotion programs from physical exercises focus on protocols that aim mainly for multisystem adaptations [4].

In this context, considerable attention has been given to Multicomponent Training (MCT) methodologies with emphasis on the stimulation of different physical qualities (balance, flexibility, cardiorespiratory capacity, muscle strength and power) in the same session

Citation: de Resende-Neto AG, do Nascimento MA, Aragão-Santos JC, Andrade BCO, Vasconcelos ABS, et al. (2019) Effects of Multicomponent Training on Functional Fitness and Quality of Life in Older Women: A Randomized Controlled Trial. Int J Sports Exerc Med 5:126. doi.org/10.23937/24695718/1510126

Accepted: April 23, 2019; Published: April 25, 2019

Copyright: (C) 2019 de Resende-Neto AG, et al. This is an open-access article distributed under the terms of the Creative Commons Attribution License, which permits unrestricted use, distribution, and reproduction in any medium, provided the original author and source are credited. 
and movements, directed for the daily living of the older adult [5], which involves the simulation of daily activities performed in a resistance training facility, contemplating multistage and multi-articular movements. The exercises also are performed at maximum concentric speed and associated with stabilization movements, aiming to improve neuromuscular efficiency and strength of the trunk [6].

Given these aspects, Cadore, et al. [7] found significant changes in maximal isometric strength and muscle power, using a combination of force exercises performed at maximum concentric velocity, balance and gait activities, after 12 weeks of intervention in fragile elderly. However, it is noteworthy in the studies available in the literature that there is no MST systematization that is easy to practice apply [5], there is also a lack of investigations analyzing its effects in specific tests to verify functional performance in daily pathway activities in elderly women.

The results of the present study can provide support to the professionals of the area, from the understanding of the effects of a training protocol with particularities not yet described in the current literature. Therefore, the purpose of the present study was to evaluate the effects of twelve weeks of multicomponent training on functional fitness and quality of life in physically active older women.

\section{Methods}

\section{Participants}

Recruitment was carried out through delivery of flyers around the city. Eighty individuals were interested in participating in the study (Figure 1), completed a questionnaire that included aspects of health, demography and physical activity. and then were selected to participate in the study if they met the following inclusion criteria: female, 60-years-old or older, had no cardiometabolic and/or neuromuscular diseases that could impede the practice of high-intensity exercises, this diagnosis being performed by a specialized medical team, physically independent in performing basic tasks of daily living, not performing physical exercise during the three months preceding the beginning of the study.

A sample size estimation was conducted with $\mathrm{G}^{*}$ Power (version 3.0.10, University Kiel, Germany). Expecting an average increase in functional fitness of $10 \%$ [8], adopting a median effect size of 0.20 , an $\alpha$ level of 0.05 , and a power $(1-\beta)$ of 0.80 , it would be necessary to include at least 50 volunteers (25 participants for each group).

The compliance of the participants was 95\% ( 34 sessions) for the MG and 85\% ( 31 sessions) for SG. The MG lost one participant due to medical reasons, and two by training frequency lower than $85 \%$. Five participants of the SG were excluded from the analysis, because they did not complete all the steps of the study.

Written informed consent was obtained from all participants included in the study after a detailed description of study procedures was provided. This investigation was conducted according to the Declaration of Helsinki and was approved by the local University Ethics Committee (number 1.021.732/CAAE: 42022915.9.0000.5546) and by the Brazilian Registry of Clinical Trials (RBR-5T9HP5).

\section{Anthropometry}

Body mass was measured to the nearest $0.1 \mathrm{~kg}$ using a calibrated electronic scale (Lider ${ }^{\circledast}$, P150C, Ribeirão Preto, São Paulo, Brazil), and height was measured to the nearest $0.1 \mathrm{~cm}$ with a stadiometer (Sanny ${ }^{\circledR}$, ES2030, Araraquara, São Paulo, Brazil). Participants wore light clothes and no shoes. Body mass index was calculated as body mass in kilograms divided by the square of height in meters. Waist and hip circumferences were measured according to World Health Organization protocol [9].

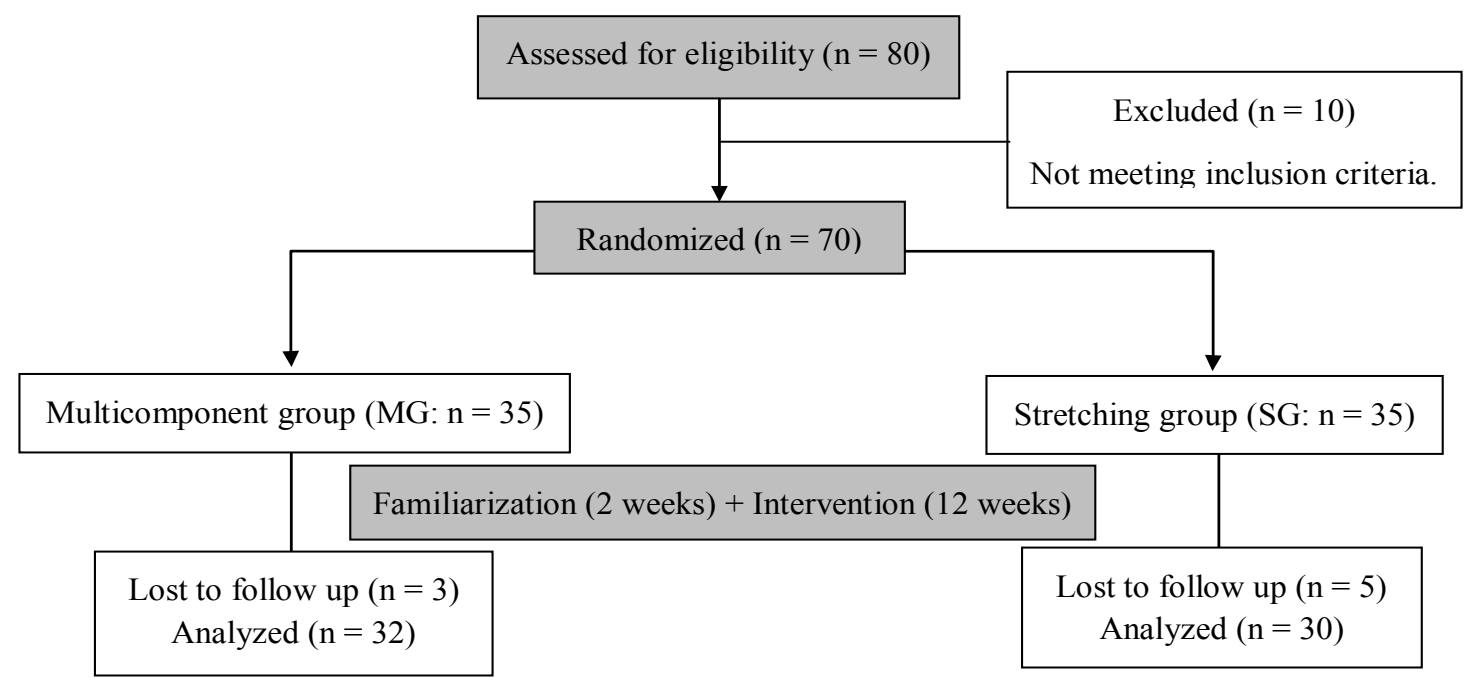

Figure 1: Flowchart for screening, recruitment, allocation, and intervention. 


\section{Quality of life}

The WHOQOL-BREF questionnaire was used to measure quality of life [10]. Briefly, it is a self-report measure with 2 general questions (on quality of life and satisfaction with health) and 24 specific questions assessing four quality of life domains: Physical (7 items), Psychological (6 items), Social Relationships (3 items), and Environmental (8 items).

\section{Functional fitness}

In the attempt to measure functional fitness, we employed Senior Fitness Test battery, validated by Rikli and Jones [11], with tests that evaluate physical fitness components (flexibility, agility/dynamic balance, muscular strength of lower and upper limbs, and cardiorespiratory capacity) to perform normal daily activities in a safe and independent way, without undue fatigue.

During the measures, the examiners were blinded to the intervention groups. During the tests, verbal encouragement was given to all participants to motivate them to perform each test action as fast as possible.

\section{Intervention program}

Multicomponent group (MG): After pre-familiarization tests, the MG underwent two weeks of familiarization, in which $50 \%$ of the planned intensity for the first session was applied. Afterwards, the participants performed a MCT during 12 weeks, three times a week, non-consecutively, composed by exercises in movement

Table 1: General description of multicomponent training sessions.

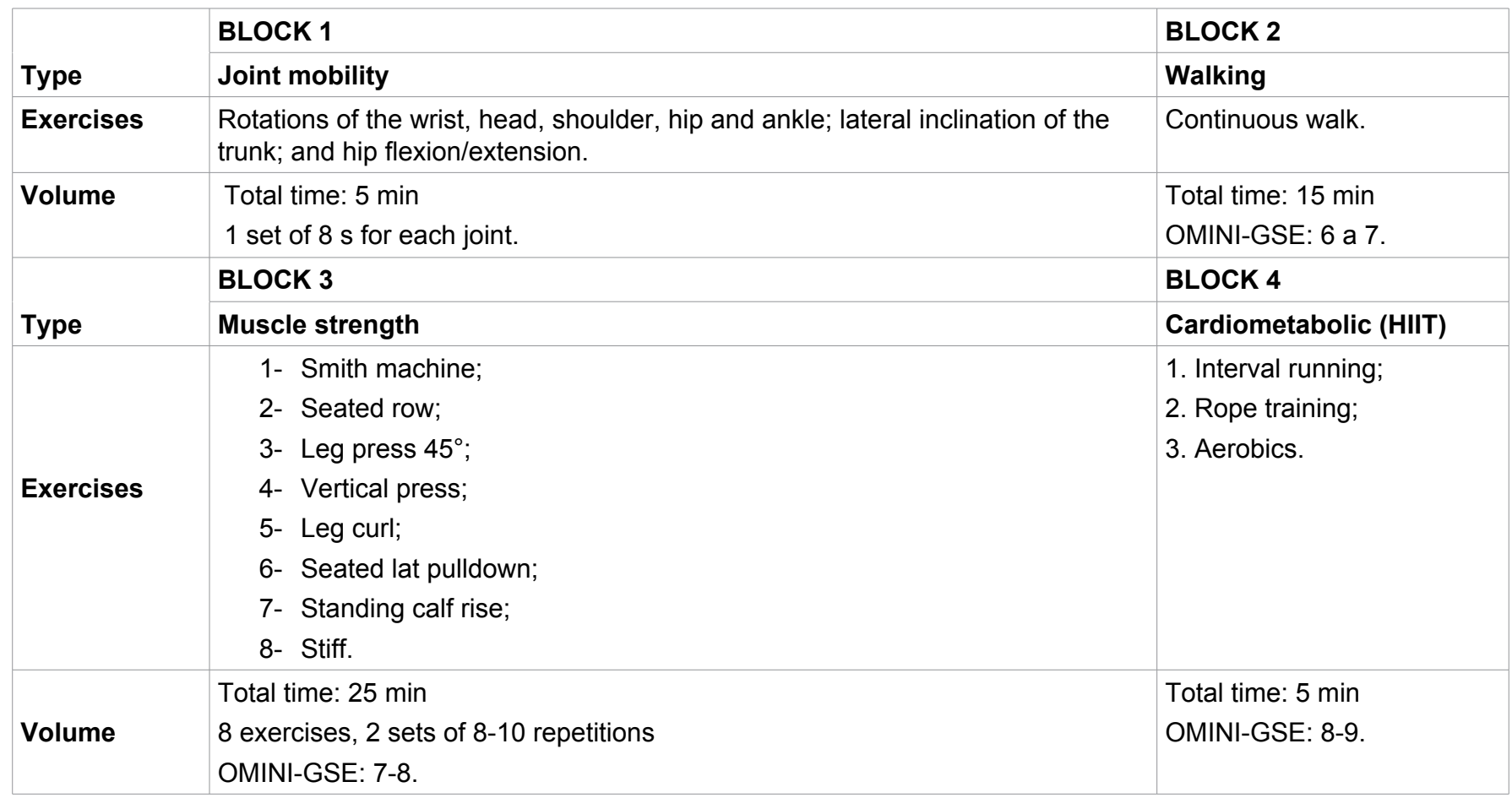
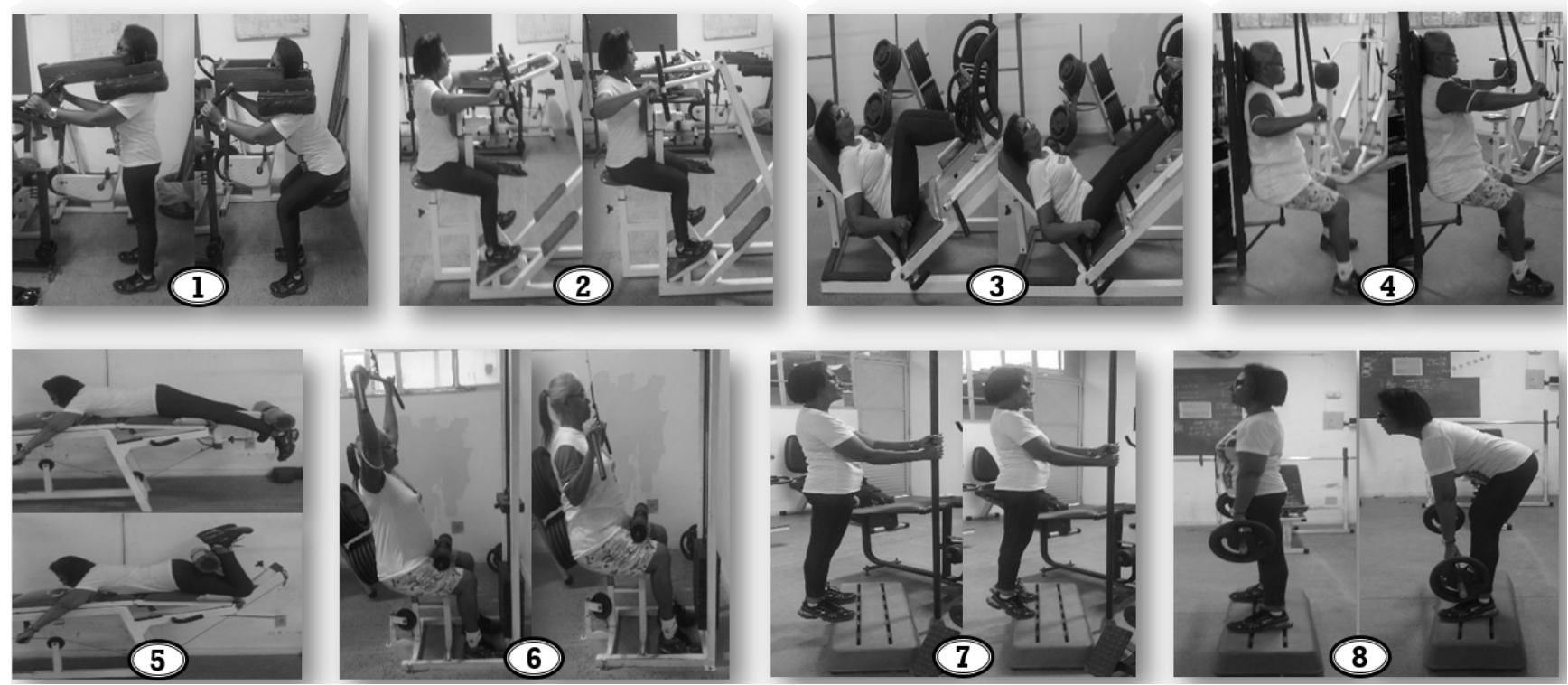

Figure 2: Main exercises performed during multicomponent training sessions. 
patterns commonly used in daily activities, at maximum concentric speed, under time constraints.

Each session was divided into four blocks: 1: 5 min of mobility for the main joints required in daily activities; 2 : 15 min of continuous walking; 3: 25 min of exercises for lower, upper and middle zone limbs, organized in circuit and focusing on movement patterns essential for daily activities (pulling, pushing and squatting); and 4: 5 min of intermittent activities (Table 1).

In block 3 all participants trained in pairs, and were supervised by experienced physical education professionals, whose responsibility was to maintain established protocols and ensure safety. The OMNI-GSE scale [12] was used to control the intensity, in which the volunteers were instructed to choose a single score that reflected their degree of fatigue, during and after each training block. The addition of external load during training period occurred from a score 6 (easy) on the OMINI-GSE scale, and with the number of repetitions performed until spontaneous fatigue or inability to sustain exercise with quality, for maintenance of 8 to 10 repetitions with $1 \mathrm{~s}$ cadence in the concentric phase and $2 \mathrm{~s}$ in the eccentric phase. The training density was $1 / 1$ (30 s of work and $30 \mathrm{~s}$ of recovery and transition between the stations) (Figure 2).

In the HIIT exercises (Block 4), collective activities with an executable motor complexity were used, following a density of $30 \mathrm{~s}$ of work per $30 \mathrm{~s}$ of transition between the following stations:

1) Interval running: In a space of 30 meters, groups of five participants were separated. Of these participants, three formed a column behind a cone and the other two formed another column at a distance of 20 meters. Working time consisted of walking this distance with maximum speed and recovery allowed while the other participants in the group performed the sprints. The total volume was 8-12 sprints per individual.

2) Classic aerobics gymnastics: In this activity, the density was controlled by musical bpm (high intensity: 150 - 165 bpm and low intensity of 130-145 bpm). It was used rhythmic movements of executable complexity, with displacements in the recovery phase, and jumps or rapid movements in the effort phase.

3) Rope training: Activity consisted of groups with equal numbers of participants at the ends of the training rope. The groups were oriented to pull at maximal strength. To achieve the maximal effort in the estimated time, two coaches were positioned by the middle of the rope to equalize the forces between the groups. The total volume was eight efforts per individual.

Stretching group (SG): The SG performed a stretching training program, 3 times a week, during 12 weeks. The training session lasted $50 \mathrm{~min}$, and was composed by 18 stretching exercises, executed in a submaximal range of motion, 2 sets of 20 s each exercise, for the whole body (neck, shoulders, trunk, lower and upper body major muscle groups), in addition to relaxation activies with no pysical efforts [13].

\section{Statistical analysis}

The data were expressed as means standard deviations and percentage change. Normality was checked by the Shapiro-Wilk's test and Levene's test was used to analyze the homogeneity of variances. Analysis of variance (ANOVA) $2 \times 2$ for repeated measures was used for comparisons between groups for all variables. When F-ratio was significant, Bonferroni's post hoc test was employed to identify the mean differences. The effect size (ES) was calculated as post-training mean minus pre-training mean divided by pooled standard deviation of pre-training and post-training [14]. Reproducibility was assessed by ICC. For all analyses, a $\mathrm{P}<0.05$ was accepted as statistical significant. The data were stored and analyzed using Statistical Package for the Social Sciences (SPSS), version 22.0.

\section{Results}

Table 2 depicts general characteristics of both groups at pre-training. There were no significant differences between groups for the variables.

According to Table 3, the MG presented significant changes in all variables after the intervention, with greater scores than SG regarding balance/agility ( $p$ $=0.001$ ), upper and lower limb muscle strength ( $p=$ $0.001)$ cardiorespiratory fitness $(p=0.021)$, and quality of life ( $p=0.031)$, with ES ranging from moderate to large. However, no differences were found between groups for lower limb flexibility (sit-and-reach test) and shoulder mobility (back scratch) ( $p \geq 0.05)$.

\section{Discussion}

The main results of the present study were the

Table 2: General characteristics of the groups at baseline.

\begin{tabular}{|c|c|c|c|}
\hline Variables & MG (n = 32) & SG $(n=30)$ & $p$ \\
\hline Age (years) & $65.28 \pm 4.96$ & $64.40 \pm 3.68$ & 0.474 \\
\hline Body mass (kg) & $66.86 \pm 13.89$ & $62.75 \pm 11.53$ & 0.237 \\
\hline Height (cm) & $151.34 \pm 6.30$ & $154.14 \pm 5.72$ & 0.071 \\
\hline Body mass index $(\mathrm{kg} / \mathrm{m})^{2}$ & $29.13 \pm 5.48$ & $26.40 \pm 4.66$ & 0.137 \\
\hline WHR (WC/HC) & $0.90 \pm 0.08$ & $0.90 \pm 0.08$ & 0.910 \\
\hline
\end{tabular}

$\mathrm{WC}=$ waist circumference, $\mathrm{HC}=$ hip circumference, $\mathrm{WHR}=$ waist-hip ratio. 
Table 3: Functional fitness and quality of life pre and post intervention in older women.

\begin{tabular}{|l|l|l|l|l|l|l|l|l|}
\hline Variables & \multicolumn{3}{|l|}{ Multicomponent group (n= 32) } & \multicolumn{3}{l|}{ Stretching group (n= 30) } \\
\hline & Pre & Post & $\Delta \%$ & ES & Pre & Post & $\Delta \%$ & ES \\
\hline Sit-and-reach (cm) & $3.35 \pm 7.38$ & $6.15 \pm 7.33^{*}$ & 83.58 & 0.38 & $3.45 \pm 9.38$ & $6.11 \pm 10.33^{*}$ & 77.10 & 0.28 \\
\hline Back scratch (cm) & $-5.47 \pm 6.72^{\#}$ & $-3.70 \pm 6.48^{*}$ & 47.84 & 0.26 & $-1.17 \pm 6.79$ & $0.38 \pm 7.09^{*}$ & 132.48 & 0.23 \\
\hline Time up go (s) & $4.84 \pm 0.57$ & $4.36 \pm 0.44^{*} . \#$ & 9.92 & 0.84 & $4.70 \pm 0.47$ & $4.88 \pm 0.56$ & -3.83 & -0.38 \\
\hline $\begin{array}{l}\text { Sit and stand } \\
\text { (repetitions) }\end{array}$ & $17.50 \pm 3.55$ & $20.18 \pm 4.48^{*} . \#$ & 15.31 & 0.75 & $16.86 \pm 2.77$ & $16.73 \pm 1.96$ & -0.77 & -0.05 \\
\hline $\begin{array}{l}\text { Elbow flexion } \\
\text { (repetitions) }\end{array}$ & $21.23 \pm 3.86$ & $24.18 \pm 4.03^{*} . \#$ & 13.90 & 0.76 & $20.91 \pm 4.25$ & $20.54 \pm 3.56$ & -1.77 & -0.09 \\
\hline \begin{tabular}{l} 
Six-minute walk (m) \\
\hline Quality of life (points)
\end{tabular} & $558.00 \pm 53.29$ & $581.14 \pm 48.82^{*} . \#$ & 4.15 & 0.43 & $561.11 \pm 46.15$ & $547.25 \pm 52.90$ & -2.47 & -0.30 \\
\hline
\end{tabular}

${ }^{*} \mathrm{P}<0.05$ vs. pre, ${ }^{\#} \mathrm{P}<0.05$ vs. Stretching group, $\mathrm{ES}=$ effect size, $\Delta \%=$ Percent change.

positive effects on all functional fitness components from a multicomponent protocol with focus on muscle power in actions commonly used in daily activities, where MG showed in 12 weeks increases of $11.92 \%$ in agility/dynamic balance, $26.62 \%$ in lower limb muscle strength, $17.72 \%$ in upper limb muscle strength, $6.19 \%$ in cardiorespiratory capacity and $7.95 \%$ in quality of life when compared to SG. In fact, in physically active older adults, programs that stimulate the different components of physical fitness into functional actions seem to be the most effective intervention for improving general physical fitness and preventing disabilities $[5,15]$.

The investigation of Freiberger, et al. [16] with a training program focusing on strength, balance and endurance, which is similar to ours, showed significant changes on agility/dynamic balance, mobility, muscle strength, and walking speed. However, it is important to mention that the protocol of the present study was more efficient in the physical performance, since there was an increase of activities of articular mobility and intermittent of high intensity to the exercises of muscle strength and dynamic balance.

Regarding dynamic agility/balance, the augments on MG can be attributed to its relationship with muscle power [17], whose stimulus was focused in the present intervention. Exercises performed at maximum concentric velocity contribute to improved neuromuscular performance by reducing antagonist coactivation and increased activation of type II fibers [2], Thus, Bassey, et al. [18] identified positive and significant correlations ( $r=0.65-0.88$ ) of lower limb power with measures of functional performance (sit and stand up, climb stairs and walk) in nonagenarians, indicating muscular power as a variable that deserves attention in exercise programs for the older adult.

The adaptations provided by MG in muscle strength can be justified by adaptations commonly observed from resistance training with weights, such as increased recruitment of motor units, improved intra- and intermuscle coordination, reduction in the number of non-contractile tissues, and improved energy availability $[19,20]$. With an intervention similar to that of the present study, Cadore, et al. [7] found significant increases in muscle power, maximal dynamic and isometric strength, accompanied by significant changes in the quadriceps total cross-sectional area with low fat infiltration and high muscle density after 12 weeks of multicomponent training in the elderly.

Regarding cardiorespiratory fitness and walking ability performance, significant changes on MG may be derived from mobility exercises, especially for the ankle and hip joints [21], in addition to the metabolic characteristics of walking, of resistance training in a circuit format [22] and intermittent high-intensity activities [23], promoting changes in muscle elasticity and in the mechanisms responsible for the transport and use of oxygen. By suggesting some of the key adaptive responses to combined aerobic and resistance exercise protocols, three times a week, also at an intensity of approximately $80 \%$ of $1 \mathrm{RM}$, Frontera, et al. [24] observed improvement in VO2 max accompanied by a $15 \%$ increase in the amount of capillaries per fiber and $38 \%$ increase in the activity of oxidative enzymes.

In the present study, the protocols applied were equally efficient in improving flexibility, and this adaptation may be due to the mobility exercises performed in the first block of the interventions and the execution of multi-articular exercises in large amplitudes in the MG and by the specificity of the training in the GA [25]. Corroborating our findings, Correia, et al. [26] stated that strength training is efficient in decreasing joint stiffness and muscle elasticity in the elderly, regardless of the protocol of exercise applied, suggesting as main mechanisms the reduction of the rate of muscular spindle firing and decrease of non-contractile tissues.

Improvement in quality of life can be considered as a global result of participation in systematic exercise programs aimed at increasing muscle strength in functional tasks, involving aspects such as lifestyle change, improvement of health levels, physical well-being and psychological reduction, disease reduction, and improved 
social interaction [27]. These results are consistent with the findings of Whitehurst, et al. [28] who when assessing quality of life through the Short-Form Health Survey (SF-36) and observed increases in their functioning and physical vitality as a consequence of improved functional capacity after the multicomponent exercise circuit.

Currently it is evident that the changes provided by the MCT in the neuromotor control were reflected in the improvement of the functional capacities, repercussion in the improvement of the quality of life [29]. Corroborating also with this information, Villareal, et al. [30] observed a $21 \%$ increase in general physical performance and consequent $24 \%$ improvement in quality of life after six months of combined training in obese elderly, also showing the multisystem benefits of similar proposals to the present investigation.

The present investigation focused on analyzing adaptive responses to a training protocol with particularities not yet scientifically tested and, although it has provided important information on the benefits of MCT in functional fitness in physically active older women, some limitations need to be addressed: o intervention period was quiet short, our sample was composed only by older women, which does not allow the extrapolation of results (i.e. to older men and sedentary), not to mention lack of measures of body composition components.

\section{Conclusion}

Multicomponent training is effective in improving physical fitness and quality of life in physically active older women. The present research shows that a physical training program designed to stimulate the various systems that promote health benefits for the older adult, should focus on improving the components of physical fitness, in movement patterns commonly used in the activities of daily living, performed at maximum concentric speed, respecting safety criteria, effectiveness and functionality.

\section{Conflict of Interest}

The authors declare no conflict of interest with the contents of this article.

\section{Author Contributions}

AGRN and MESG designed research; AGRN, MAN and DRPS performed experiments; AGRN and JMS analyzed data; AGRN and MESG interpreted results of experiments; AGRN drafted manuscript; AGRN, RSMN and JMS edited and revised manuscript; AGRN, MESG and JMS approved final version of manuscript.

\section{Acknowledgments}

No external financial support.

\section{References}

1. Westcott WL (2012) Resistance training is medicine: effects of strength training on health. Curr Sports Med Rep 11: 209-216.
2. Byrne C, Faure C, Keene DJ, Lamb SE (2016) Ageing, Muscle Power and Physical Function: A Systematic Review and Implications for Pragmatic Training Interventions. Sports Med 46: 1311-1332.

3. American College of Sports Medicine, Chodzko-Zajko WJ, Proctor DN, Fiatarone Singh MA, Minson CT, et al. (2009) American College of Sports Medicine position stand. Exercise and physical activity for older adults. Med Sci Sports Exerc 41: 1510-1530.

4. Liu C, Shiroy DM, Jones LY, Clark DO (2014) Systematic review of functional training on muscle strength. physical functioning. and activities of daily living in older adults. Eur Rev Aging Phys Act 11: 95-106.

5. Bouaziz W, Lang PO, Schmitt E, Kaltenbach G, Geny B, et al. (2016) Health benefits of multicomponent training programmes in seniors: a systematic review. Int J Clin Pract 70: 520-536.

6. Heredia JR, Peña G, Moral S (2011) Entrenamiento funcional en Sañudo: Nuevas orientaciones para una actividad física saludable en centros de fitness. Editorial Wanceulen.

7. Cadore EL, Casas-Herrero A, Zambom-Ferraresi F, Idoate F, Millor N, et al. (2014) Multicomponent exercises including muscle power training enhance muscle mass power output and functional outcomes in institutionalized frail nonagenarians. Age 36: 773-785.

8. Resende-Neto AG, Feitosa-Neta ML, Santos MS, Teixeira CVLS (2016) Treinamento funcional versus treinamento de força tradicional: efeitos sobre indicadores da aptidão física em idosas pré-frageis. Motricidade 12: 44-53.

9. (2000) Obesity: preventing and managing the global epidemic. Report of a WHO consultation. World Health Organ Tech Rep Ser 894: i-xii, 1-253.

10. Fleck MP, Chachamovich E, Trentini C (2006) Development and validation of the Portuguese version of the WHOQOLOLD module. Rev Saude Publica 40: 785-791.

11. Rikli RE, Jones CJ (2013) Development and validation of criterion-referenced clinically relevant fitness standards for maintaining physical independence in later years. Gerontologist 53: 255-267.

12. Da Silva-Grigoletto ME, Viana-Montaner $\mathrm{BH}$, Heredia JR, Mata F (2013) Validación de la escala de valoración subjetiva del esfuerzo OMNI-GSE para el control de la intensidad global en sesiones de objetivos múltiples en personas mayores. Kronos 12: 32-40.

13. Nelson A, Kokkonen J (2007) Anatomia do alongamento: guia ilustrado para aumentar a flexibilidade e a força muscular. 1. ed. Barueri, SP: Manole.

14. Cohen J (2013) Statistical power analysis for the behavioral sciences. Rutledge.

15. Clemson L, Fiatarone Singh MA (2012) Integration of balance and strength training into daily life activity to reduce rate of falls in older people (the LiFE study): Randomized parallel trial. BMJ.

16. Freiberger E, Häberle L, Spirduso WW, Zijlstra GA (2012) Long-term effects of three multicomponent exercise interventions on physical performance and fall-related psychological outcomes in community-dwelling older adults: A randomized controlled trial. J Am Geriatr Soc 60: 437-446.

17. Izquierdo M, Aguado X, Gonzalez R, López JL, Häkkinen K (1999) Maximal and explosive force production capacity 
and balance performance in men of different ages. Eur $J$ Appl Physiol Occup Physiol 79: 260-267.

18. Bassey EJ, Fiatarone MA, O'Neill EF, Kelly M, Evans WJ, et al. (1992) Leg extensor power and functional performance in very old men and women. Clin Sci (Lond) 82: 321-327.

19. Kraemer WJ, Ratamess NA, French DN (2002) Resistance training for health and performance. Curr Sports Med Rep 1: $165-171$.

20. Borde, Hortobágyi T, Granacher U (2015) Dose-response relationships of resistance training in healthy old adults: a systematic review and meta-analysis. Sports Med 45: 16931720.

21. Stathokostas L, Little RM, Vandervoort AA, Paterson DH (2012) Flexibility training and functional ability in older adults: a systematic review. J Aging Res 2012: 306818.

22. Romero-Arenas S, Martínez-Pascual M, Alcaraz PE (2013) Impact of resistance circuit training on neuromuscular. cardiorespiratory and body composition adaptations in the elderly. Aging Dis 4: 256-263.

23. Milanovic Z, Sporiš G, Weston M (2015) Effectiveness of High-Intensity Interval Training (HIT) and Continuous Endurance Training for VO2maxImprovements: A Systematic Review and Meta-Analysis of Controlled Trials. Sports Med 45: 1468-1481.
24. Frontera WR, Meredith CN, O'Reilly KP, Evans WJ (1990) Strength training and determinants of VO2max in older men. J Appl Physiol (1985) 68: 329-333.

25. Oliveira LC, Oliveira RG, Almeida Pires-Oliveira DA (2016) Comparison between static stretching and the Pilates method on the flexibility of older women. J Bodyw Mov Ther 20: $800-806$.

26. Correia M, Menêses A, Lima A, Cavalcante B, Ritti-Dias R (2014) Efeito do treinamento de força na flexibilidade: uma revisão sistemática. Rev Bras Ativ Fis e Saúde 19: 3-11.

27. Roberts CE, Phillips LH, Cooper CL, Gray S, Allan JL (2017) Effect of Different Types of Physical Activity on Activities of Daily Living in Older Adults: Systematic Review and MetaAnalysis. J Aging Phys Act 25: 653-670.

28. Whitehurst MA, Johnson BL, Parker CM, Brown LE, Ford AM (2005) The benefits of a functional exercise circuit for older adults. J Strength Cond Res 19: 647-651.

29. Tricco AC, Thomas SM, Veroniki AA, Hamid JS, Cogo E, et al. (2017) Comparisons of Interventions for Preventing Falls in Older Adults: A Systematic Review and Meta-analysis. JAMA 318: 1687-1699.

30. Villareal DT, Aguirre L, Gurney AB, Waters DL, Sinacore DR, et al. (2017) Aerobic or Resistance Exercise, or Both, in Dieting Obese Older Adults. N Engl J Med 376: 1943-1955. 